Argonne

\title{
Validation of Spent Fuel Dose Rate Calculations Using NDA Measurement Campaign Data
}

Nuclear Science and Engineering Division 


\section{About Argonne National Laboratory}

Argonne is a U.S. Department of Energy laboratory managed by UChicago Argonne, LLC under contract DE-AC02-06CH11357. The Laboratory's main facility is outside Chicago, at 9700 South Cass Avenue, Argonne, Illinois 60439. For information about Argonne and its pioneering science and technology programs, see www.anl.gov.

\section{DOCUMENT AVAILABILITY}

Online Access: U.S. Department of Energy (DOE) reports produced after 1991 and a growing number of pre-1991 documents are available free at OSTI.GOV (http://www.osti.gov/), a service of the US Dept. of Energy's Office of Scientific and Technical Information.

Reports not in digital format may be purchased by the public from the National Technical Information Service (NTIS):

U.S. Department of Commerce

National Technical Information Service

5301 Shawnee Rd

Alexandria, VA 22312

www.ntis.gov

Phone: (800) 553-NTIS (6847) or (703) 605-6000

Fax: (703) 605-6900

Email:orders@ntis.gov

Reports not in digital format are available to DOE and DOE contractors from the Office of Scientific and Technical Information (OSTI):

U.S. Department of Energy

Office of Scientific and Technical Information

P.O. Box 62

Oak Ridge, TN 37831-0062

www.osti.gov

Phone: (865) 576-8401

Fax: (865) 576-5728

Email: reports@osti.gov

\section{Disclaimer}

This report was prepared as an account of work sponsored by an agency of the United States Government. Neither the United States Government nor any agency thereof, nor UChicago Argonne, LLC, nor any of their employees or officers, makes any warranty, express or implied, or assumes any legal liability or responsibility for the accuracy, completeness, or usefulness of any information, apparatus, product, or process disclosed, or represents that its use would not infringe privately owned rights. Reference herein to any specific commercial product, process, or service by trade name, trademark, manufacturer, or otherwise, does not necessarily constitute or imply its endorsement, recommendation, or favoring by the United States Government or any agency thereof. The views and opinions of document authors expressed herein do not necessarily state or reflect those of the United States Government or any agency thereof, Argonne National Laboratory, or UChicago Argonne, LLC. 


\section{Validation of Spent Fuel Dose Rate Calculations Using NDA Measurement Campaign Data}

prepared by

Yan Cao, Matthew Boyd, and Bo Feng

Nuclear Science and Engineering Division, Argonne National Laboratory

$09 / 02 / 2020$ 


\title{
Validation of Spent Fuel Dose Rate Calculations Using NDA Measurement Campaign Data
}

\author{
Yan Cao, Matthew Boyd, and Bo Feng \\ Argonne National Laboratory \\ Updated: May 29, 2020
}

\section{Introduction}

The predicted radiation gamma dose rate is a key parameter to determine if a spent nuclear fuel assembly is self-protected from misuse as well as an indicator for worker/inspector safety. Recent studies $[1,2,3]$ showed that using state-of-the-art techniques for dose rate calculations, including the one adopted for this study, the numerical calculations of the gamma dose rates are three times lower than those from the most commonly-cited reference values for spent LWR fuel [4] used by domestic and international agencies. With only a few publically available experimental data points worldwide for this type of benchmark study, the gamma flux measurements from the Spent Fuel Non Destructive Assay (NDA) measurement campaign can be used to help validate the physics approach used in calculating gamma dose rates [5]. Specifically, this data would validate the gamma flux calculation from spent fuel, which is a key component of these multi-physics techniques for dose rate assessments; dose rate measurements were not part of the NDA campaign. These data are primarily the passive gamma measurements of the spent nuclear fuel assemblies from the Swedish Nuclear Fuel and Waste Management Company (SKB) [5].

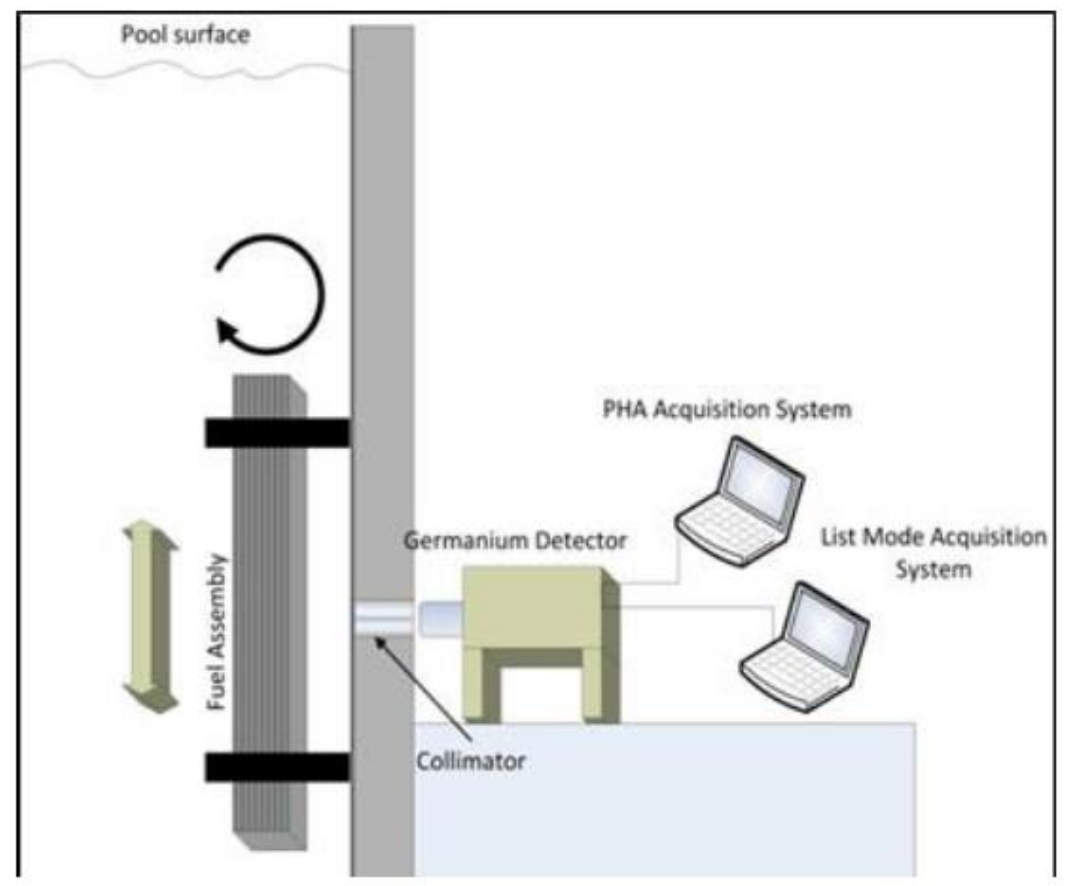

Figure 1 Schematic of experiment setup of the passive gamma measurements [6] 
The NDA data includes passive gamma fluxes that were measured for 25 PWR and 25 BWR fuel assemblies, labeled only as "PWR1, PWR2, etc." to remove identifying information, using the high-purity germanium detectors or lanthanum bromide scintillation detectors. Figure 1 shows a schematic of the experimental setup of these measurements [6]. Each fuel assembly was placed in the pool at Sweden's Central Interim Storage Facility (Clab) with one of its corners facing a steel collimator which was built into the pool wall. The fuel assembly was rotated with four corners each facing the collimator to allow four static measurements of the gamma fluxes. The fuel assembly was also moved up and down to allow integral scans along the vertical direction for the gamma fluxes at each of the four angles. Therefore, each fuel assembly has a total of 8 gamma spectra available for comparison [7].

\section{Simplified Bare Assembly (Item) Models}

The NDA data was provided to ANL from LANL in the form of measured passive gamma counts at several energy peaks in Excel spreadsheets and MCNP models of all 50 assemblies or items. These MCNP models contain detailed isotopic compositions of the fuels, source terms, cladding and structural information, and assembly geometry. Note that the experimental environment (pool, detectors, collimator, etc.) was not included in these MCNP models. Nevertheless, in terms of the fuel material description, the models were deemed to contain too much compositional detail for the purposes of dose rate calculations, which would significantly slow down the calculation process. This section describes how these MCNP models of bare assemblies were simplified by ANL for the sole purpose of speeding up the calculations while not losing too much accuracy.

Shortly after the measurements were obtained from the NDA campaign, significant modeling work was already performed by various laboratories to model the irradiation and decay of those fuel assemblies [8]. At ORNL, the ORIGAMI code was used in the fuel burnup and fuel decay simulations to provide the compositions in the MCNP models received by ANL. ORIGAMI was used to generate nuclide compositions for each axial node of each fuel pin in a fuel assembly. For the SKB PWR fuel assemblies, each fuel pin was divided into nine axial nodes. With more than 200 fuel pins in each fuel assembly, the total number of fuel zones for one assembly is more than 1800 in one fuel assembly model. ANL received three MCNP input decks for each fuel assembly. The "Upper", "Mid" and "Lower" input decks describe the upper, middle, and lower axial parts of the fuel assembly, respectively, with vacuum boundary conditions applied outside the assembly.

To model the gamma transport and simulate the gamma spectra, ANL first combined the three MCNP input decks into one single MCNP model so that the numerical calculations can correctly count the gamma contributions from all the axial zones of the fuel assembly. The original fine discretization of different fuel burnup zones inside the fuel assembly led to a significantly large number of fuel materials and source terms which are not critical for gamma transport simulations and are almost impossible to handle in a single MCNP transport simulation.

To simplify the MCNP models, for each axial layer of the fuel assembly, the fuel pins that have similar fuel burnups and gamma sources in the ORIGAMI calculations were grouped together as one pin type. The nuclide compositions for those similar fuel zones were then homogenized to one fuel composition. The discrete gamma energy lines for those similar fuel pins were homogenized as well into one gamma source spectrum representing an average of 6 pins. Figure 2 compares the 
original gamma energy spectra with the homogenized spectrum. Clearly, the energy spectra from each of the six fuel pins are almost the same; all 6 points at each discrete energy overlap with each other and with the exception of two points, overlap with the homogenized points as well. This indicates close agreement in the source terms between the original and simplified (homogenized) assembly models.

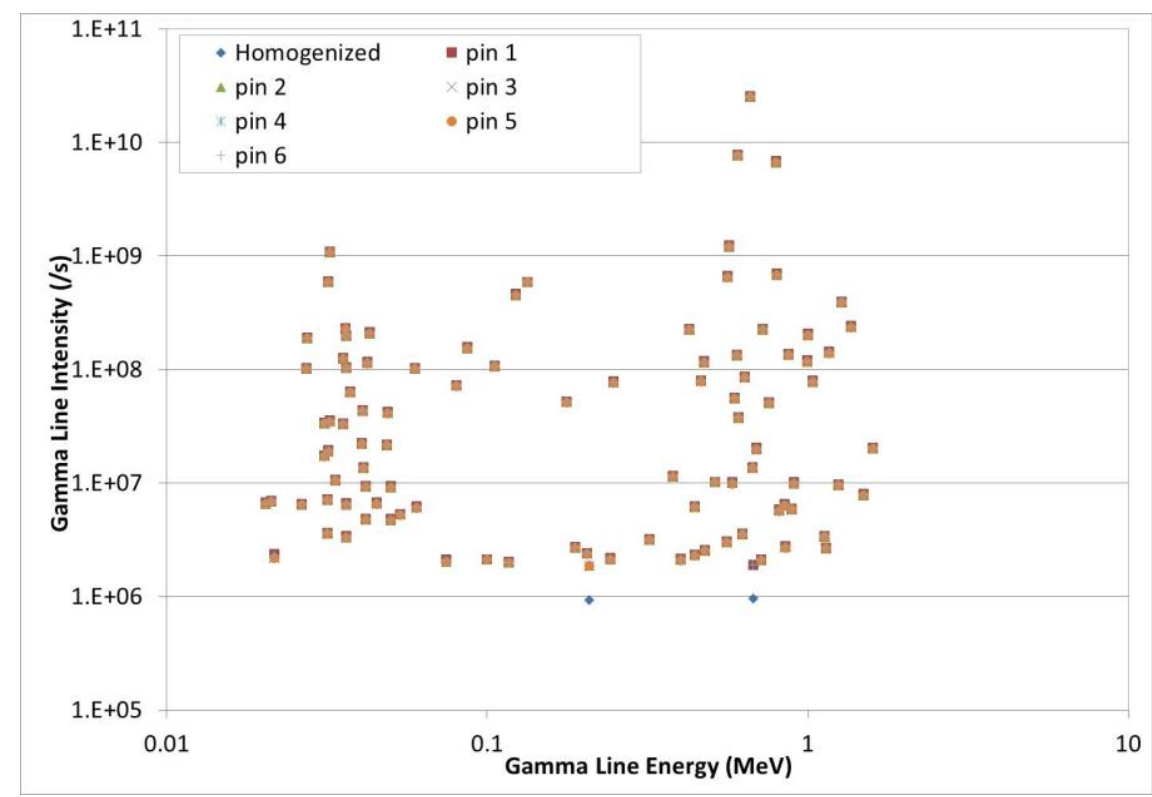

(b)

Figure 2 Example of ORIGAMI calculated gamma energy spectra

\section{Verification of the Simplified Bare Assembly (Item) Models}

To ensure that these simplified MCNP models also retained a similar level of accuracy for calculated gamma flux through water, the original MCNP model describing only the middle part of the fuel assembly and simplified MCNP bare assembly model were used in comparison studies by modeling 4 surface detectors ( $\mathrm{F} 4$ tallies) at a few centimeters away from each corner. The surface tallies (or "detectors") are the four sides of the yellow box shown for PWR1 in Figure 3(a) with a simulated "detector height" of $6 \mathrm{~cm}$ at the axial midpoint of the fuel; these tallies yield the "static" gamma fluxes. For PWR1, the average gamma flux among the four static calculations is $2.64 \mathrm{E}+12$ /s using the simplified MCNP model, which agrees with the $2.66 \mathrm{E}+12 / \mathrm{s}$ calculated using the original MCNP model. 


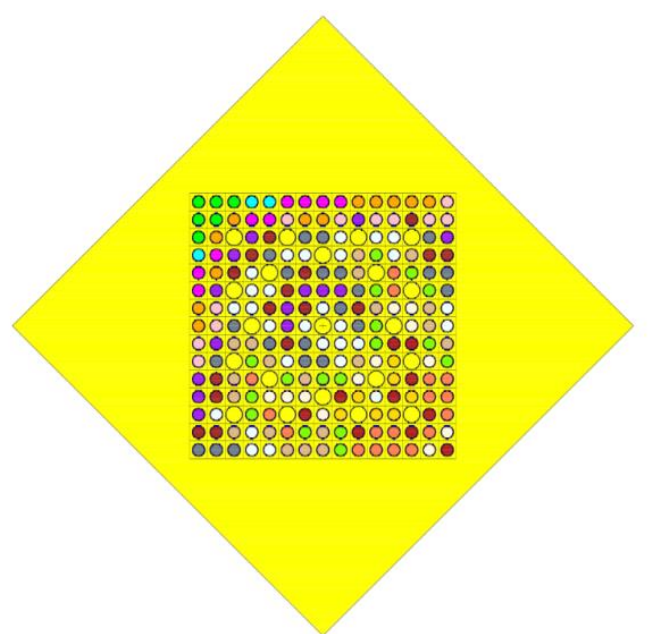

(a)

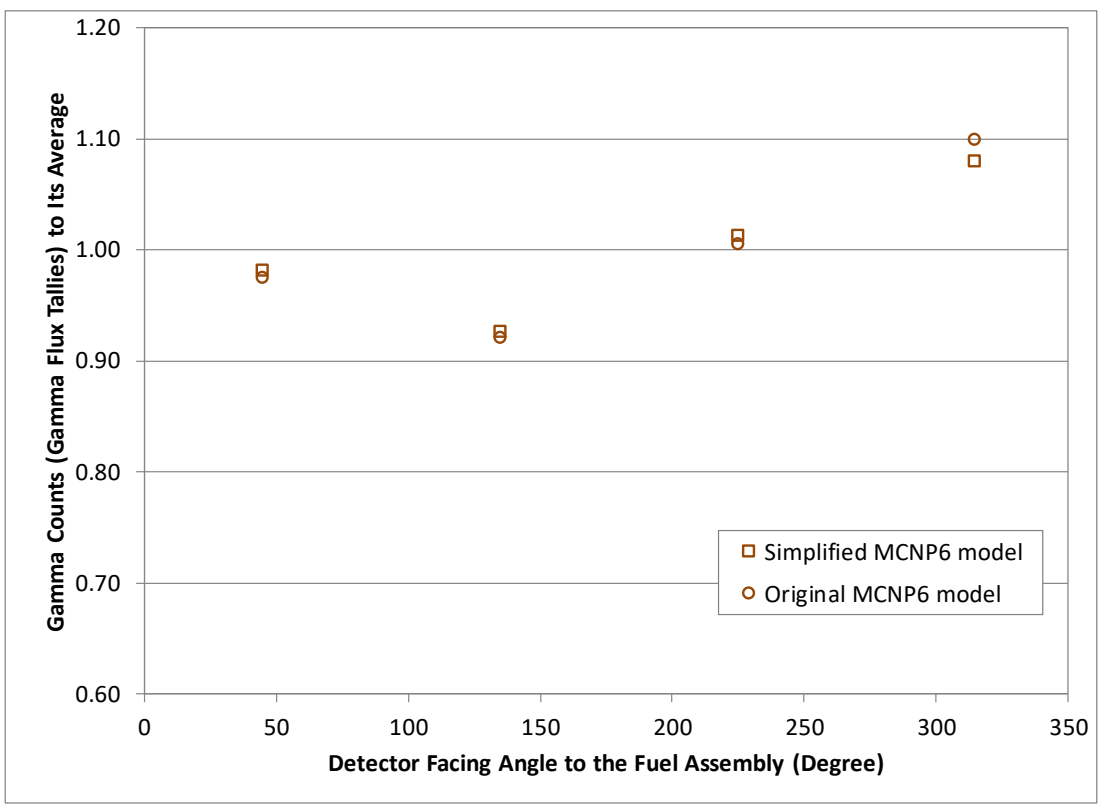

(b)

Figure 3 (a) MCNP model with the surface tallies facing four corners of the fuel assemblies. (b) Tallied gamma flux dispersion using both the simplified and original MCNP models for PWR1 In addition, Figure 3(b) shows the gamma flux dispersion (relative flux at each corner compared to the average) using both models. This dispersion along with the average static gamma fluxes indicate that the simplified MCNP model retains excellent agreement with the original MCNP models in terms of gamma transport through water.

\section{Validation of the Simplified Bare Assembly (Item) Models}

Following the same procedure, simplified MCNP models were developed for all 25 PWR fuel assemblies with the goal of comparing the calculated gamma fluxes from these models to those from the measured data. However, since these MCNP models are bare spheres and the measured data were obtained with a full experimental environment, it was only possible to compare 
normalized gamma flux values rather than absolute values. Available data provided to ANL consisted of count rates for 13 peaks from 6 isotopes: 1 from Cs-137, 5 from Cs-134, 4 from Eu154, and an additional 1 line each from K-40, Ce-144, and Rh-106. For this validation exercise, the key gamma peak for LWR dose rate calculations (662 keV from Cs-137 decay) was selected for comparison. Both the 4-side averaged static gamma measurements and the 4-side averaged scanned gamma measurements were also normalized and compared to the calculated normalized values from MCNP. In the MCNP model, the scanned flux is simply assumed to be the flux through a surface tally along the entire axial length of the fuel assembly rather than the flux within the 6 cm "detector" for the static flux.

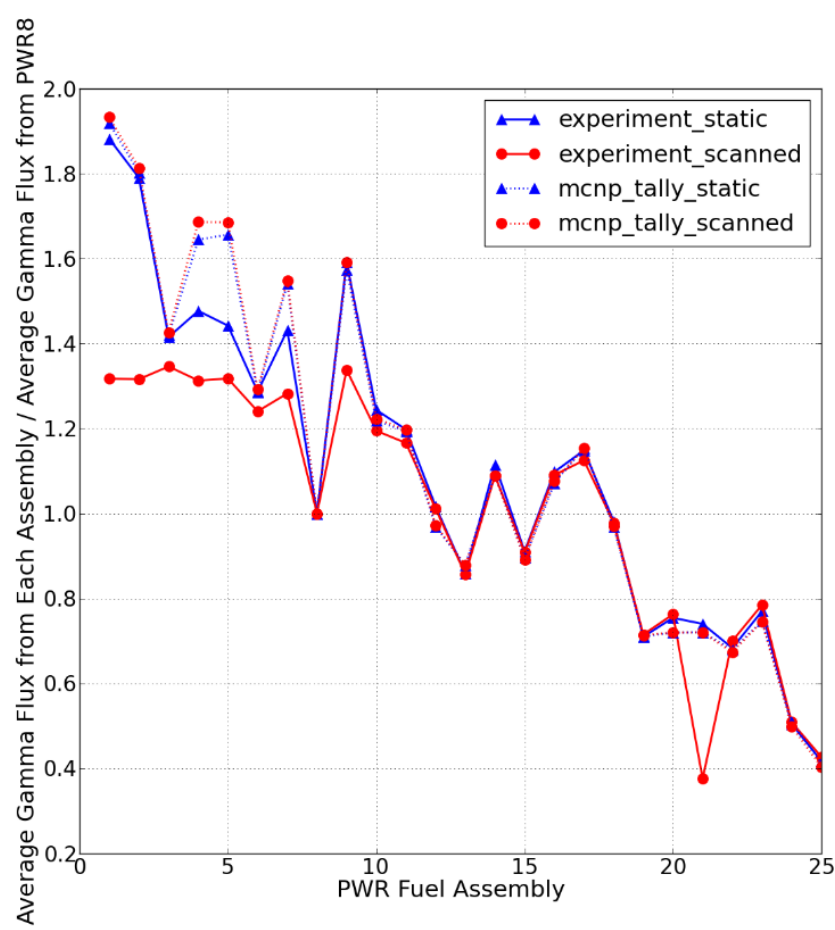

Figure 4 Average gamma counts (or flux) at $662 \mathrm{keV}$ energy level for each PWR assembly compared to those for PWR8 produced from measurements and MCNP simulations

Figure 4 shows the 4-side averaged static and scanned gamma fluxes for the $662 \mathrm{keV}$ peak calculated from MCNP and compared to those from the experiments. In order to produce this figure to compare relative results, the calculated or measured flux from each of the 25 assemblies was normalized to the calculated or measured flux from PWR8. Initially, PWR1's values were chosen as the normalization factors, but due to the large disagreements between calculated and measured scanned fluxes in the first 7 assemblies, our best guess was that PWR8 serves as the normalization assembly that allows the best agreement across all 25 assemblies.

With a few exceptions (PWR4, PWR5, and PWR7), the relative experimental static flux, calculated static flux, and calculated scanned flux are in almost exact agreement in this figure. Those three exceptions show slightly lower experimental static fluxes, assuming PWR8 has all the "correct" values. The experimental scanned flux also shows excellent agreement for only about half of the assemblies. 
The reason for the differences shown for the calculated vs. experimental scanned flux results is not clear. The MCNP model only modeled the bare fuel assembly with all the other structure materials ignored. Based on our previous knowledge, the gamma fluxes due to the irradiation of the structural materials can be significant contributions in some cases [5]. The scanned experiments read contributions of gamma fluxes from the whole fuel assembly including spacers. In addition, in the experiment, the scanned gamma fluxes were taken by moving the fuel assemblies passing the collimator slit. The exact motion of the fuel assembly is unknown. All these factors may lead to the scanned fluxes different from a simple integration of the gamma flux of the whole fuel assembly we assumed in the MCNP model. Therefore, in the later analysis, only those experimental data from static measurements are utilized in the analysis. Particularly, MCNP simulations with the full environment are limited to PWRs 1-2 for validation purposes.

\section{Experimental Setup of Gamma Measurements and Corresponding MCNP Model}

In the actual experimental setup for the passive gamma measurements, as previously shown in Figure 1, the distance from the assembly center to the pool wall was $50 \mathrm{~cm}[9,10]$. Figure 5 shows an MCNP modelof the horizontal cross section of the steel collimator consisting of two steel half cylinders $120 \mathrm{~cm}$ long and $27 \mathrm{~cm}$ in diameter built into the pool wall at $\sim 10 \mathrm{~m}$ below the surface level of the water $[11,12,13]$.

The vertical width of the collimator slit was set to $5 \mathrm{~mm}[11,13]$. The horizontal width of the slit is sufficient to view the entire quadratic of the fuel assembly at the fuel end but narrows to a $5 \mathrm{~cm}$ opening at the detector end [10]. The distance from the center of the assembly to the end of the collimator was $2.46 \mathrm{~m}$. The central axis of the detector was positioned $3 \mathrm{~mm}$ below the vertical plane of the detector to optimize the signal-to-background ratio [11].

The Clab fuel pool is steel lined, but no information could be found on the liner thickness [14]. A value of $7 \mathrm{~mm}$ was assumed for this work based on the liner thickness at the Barsebeck-2 BWR plant in Sweden [15]. Several additional attenuators were positioned after the collimator, and their composition and thickness depends on the specific measurement campaign [11]. In the work performed in 2019 fiscal year, the $3.2 \mathrm{~mm}$ lead and $1 \mathrm{~mm}$ copper from the fourth measurement campaign were assumed. After careful consideration, we believe the measurements for all PWRs were done in the third measurement campaign, and thus the attenuators in the models were updated to be $8 \mathrm{~mm}$ of lead, $21 \mathrm{~mm}$ of stainless steel, $3 \mathrm{~mm}$ of aluminum, and $1 \mathrm{~mm}$ of copper. 


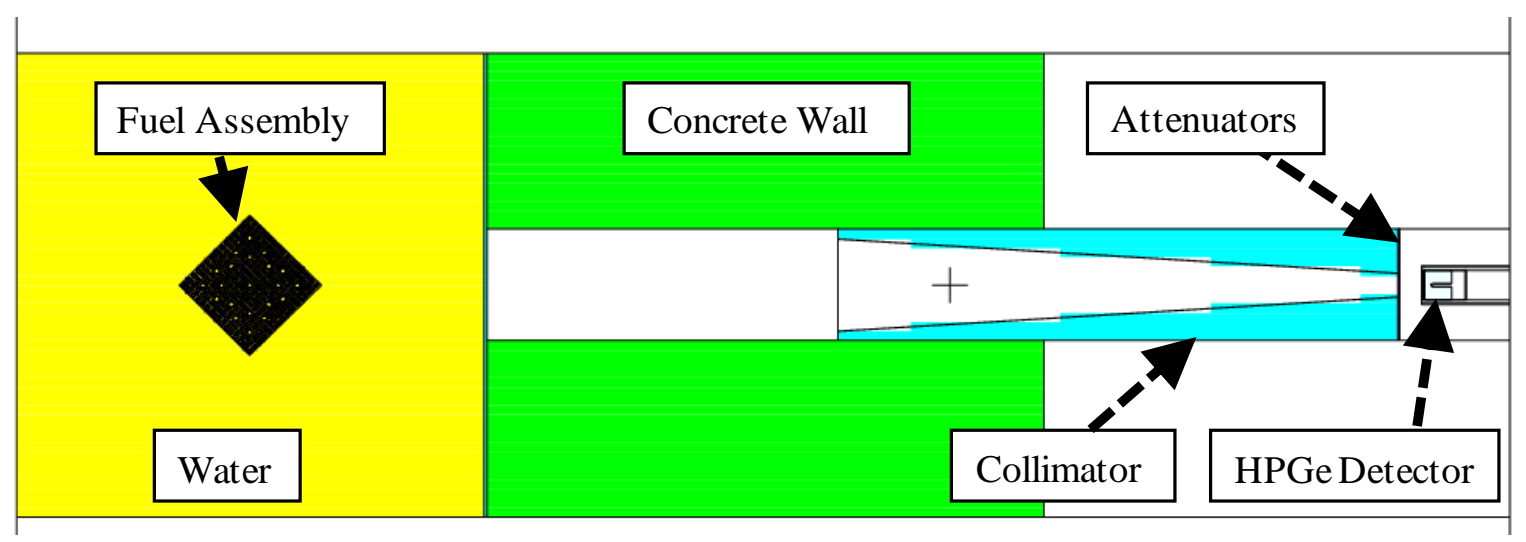

Figure 5 MCNP model horizontal cross-section at collimator slit location.

In the MCNP model, the water pool was represented as a $50 \mathrm{~cm}$ square block of water. A $7 \mathrm{~mm}$ steel liner separates the water from a $120 \mathrm{~cm}$ thick concrete wall and empty cavity for the collimator. The steel collimator begins $126 \mathrm{~cm}$ from the center of the assembly. The attenuators are located after the collimator. The experimental data provided to ANL was measured using the high-purity germanium (HPGe) detectors. For the MCNP models, an HPGe detector endcap and crystal was modeled based on typical values, obtained from the manufacturer [11]. The Ge crystal is $6.27 \mathrm{~cm}$ in diameter and $6.05 \mathrm{~cm}$ length [16]. For the model used in the experimental work, a Canberra GX4518 (45\% efficiency) was used based on reported specifications.

\section{Validation of Detector Model}

To first test the accuracy of the model for the HPGe, a simple MCNP simulation was conducted to replicate the standard relative efficiency test of the reference $3 \times 3 \mathrm{NaI}(\mathrm{Tl})$ scintillator detector [11]. In the model, a Co-60 source was placed $25 \mathrm{~cm}$ from the detector endcap face. The MCNP F8 'Pulse Height' tally was used to simulate a detector response during the photon transport and will be used in the MCNP models discussed in the next section, which include the detector and experimental setup. The F8 tally records the energy or charge deposited by each source particle and its secondary particles, and the number of pulses depositing energy in a particle energy bin are tallied. By providing an appropriate energy binning, a direct comparison can be obtained between the simulated pulse height in MCNP and the experimental count rate for a given peak, such as the ones provided for the $3 \times 3 \mathrm{NaI}(\mathrm{T} 1)$.

The resulting spectra can be seen in Figure 7 with the full spectra on the left and a zoomed in view of the Co-60 peaks on the right. The normalized tally results are plotted as a function of energy. The two Co-60 peaks can clearly be seen along with other features such as the Compton edge and continuum, the discontinuity is a plotting aberration. The tally statistical error was around $6 \%$ for the $1.33 \mathrm{MeV}$ peak. The area of the Co-60 1.33 MeV peak was then divided by the absolute efficiency of a $3 \times 3 \mathrm{NaI}(\mathrm{T} 1)$, which is $1.2 \times 10^{-3}$, to a obtain a relative efficiency of $\sim 54 \%$. The $\sim 20 \%$ difference between the nominal $45 \%$ [11] and obtained 54\% indicates relatively good agreement with the differences likely due to inaccuracies in the Ge dead layer thickness. The expected spectral features are present in Figure 6 and the model appears to respond correctly, indicating that the detectors were modeled with sufficient accuracy. 

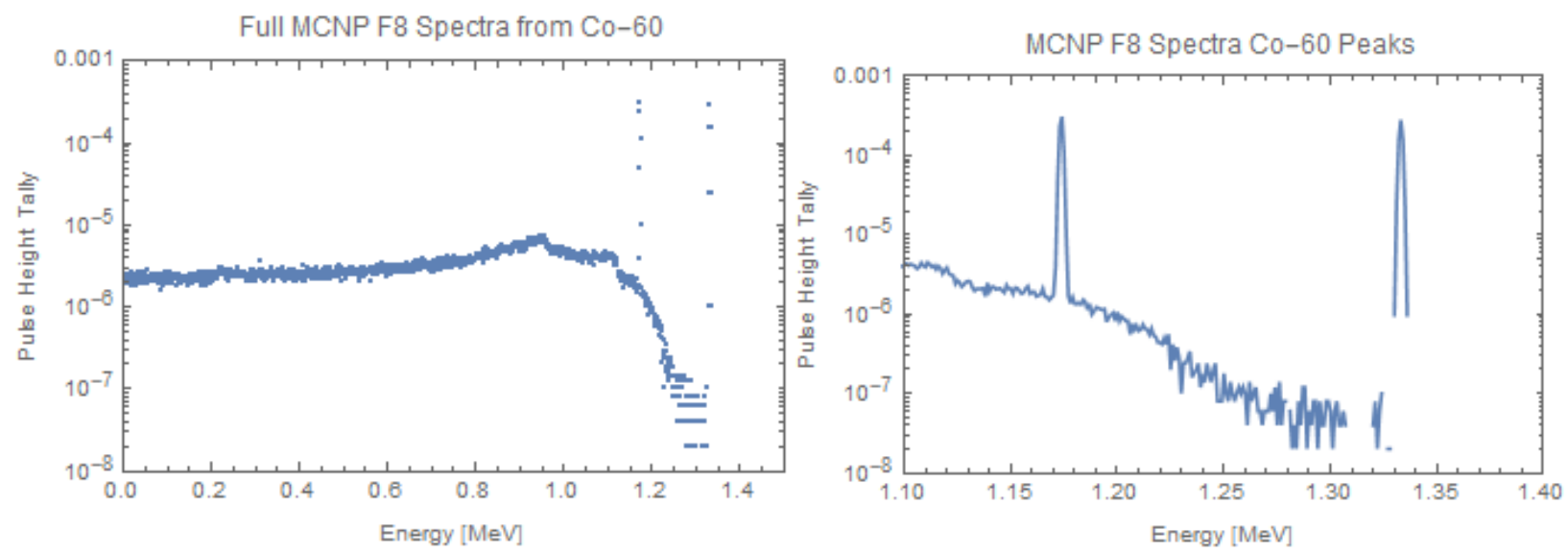

Figure $6 \mathrm{MCNP}$ F8 tally results for modeled detector $1.33 \mathrm{MeV}$ relative efficiency comparison

\section{Validation of MCNP Models of Environment}

The work discussed up to Section 4 and summarized in Figure 4 only involved MCNP bare assembly models without the experimental environment. Therefore, only the relative gamma fluxes were compare-able between the bare assembly models and the measured data, and they largely showed excellent agreement. The results in this section focus on validating the MCNP models of the assemblies within the full environment, so now the tallied detector count rates in MCNP can be directly compared with the experimental data.

The amount of the shielding material from the water, collimator, and concrete wall will significantly reduce the gammas fluxes compared to the bare assembly models. Therefore, weightwindows were used to reduce the variances of the photon flux tallies in the detector tally zone. Figure 7 shows the weight-window generated for the simulation of the PWR1 fuel assembly. The MCNP weight window tallies showed significantly increasing of particle importance along its trajectory to the detector. Given the large effort required to generate these weight windows, only the results for the first two PWR fuel assemblies are presented here.

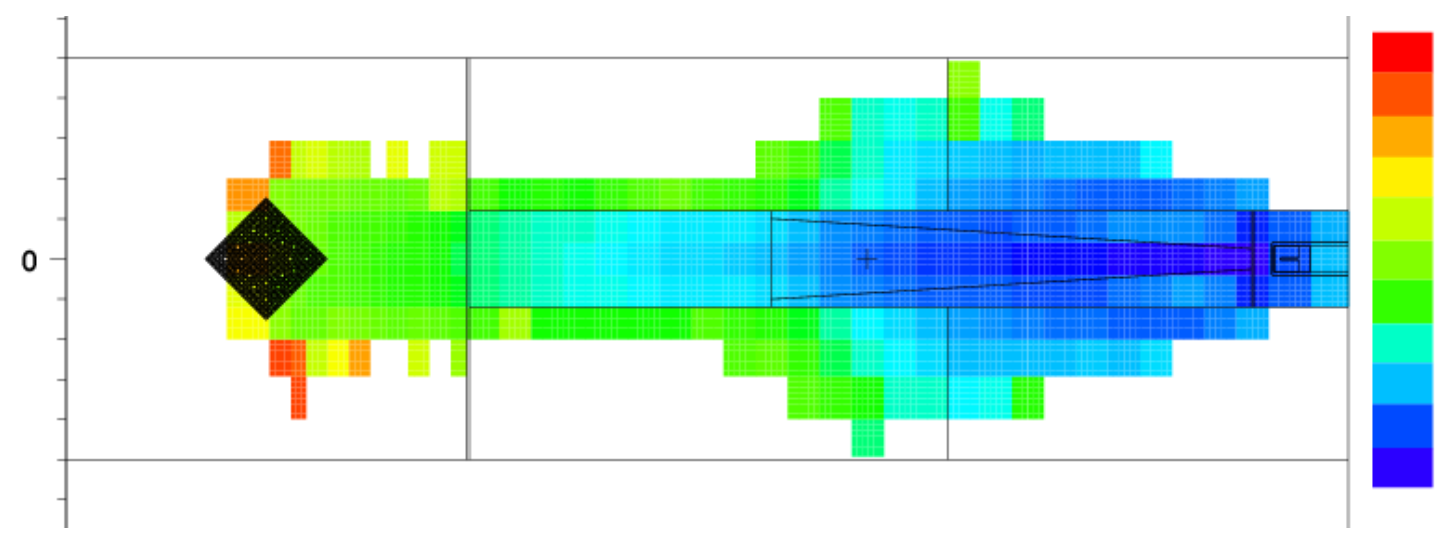

Figure 7 MCNP Generated Weight-Window (WWG) for detector tallies. 
For each fuel assembly, a total of 4 MCNP runs were performed corresponding to $90^{\circ}$ rotations of the assembly. Figure 8(a) plots the MCNP6 simulated gamma energy spectrum with its 45 degree corner facing the detector. Figure 8(b) presents a detail comparison between the MCNP tallies and the experimental data at each energy peak, with all four corners facing the detector in turn. There are two sets of experimental data, "PG-FARM" and "PG-PeakE", representing the two different techniques used to calculate the peak areas of the dominant peaks. Similarly, Figure 10 showed the same comparison for PWR2 fuel assembly. Figures 8 and 9 show good agreement between MCNP and the measurements at each peak for which there were statistically significant tallies.

For a tabulated view of these results, the average of the detector count rates at the Cs-137 and Cs134 energy peaks calculated by MCNP are shown with the experimental data in Table 1 . The experimental data are average values among the eight data points obtained from the four different angles and the techniques PG-FARM and PG-PeakG. The MCNP6 tallies are average values among the four angles. The comparison showed that for the Cs-137 $662 \mathrm{keV}$ energy peak, the numerical simulation calculated the detector count rates well, with C/E at 1.04 for PWR1 and 1.16 for PWR2. However, the C/Es have large variations from 1.03 to 1.72 at Cs-134 different energy peaks, but for dose rate purposes, the vast majority of the contribution is from the $662 \mathrm{keV}$ peak.

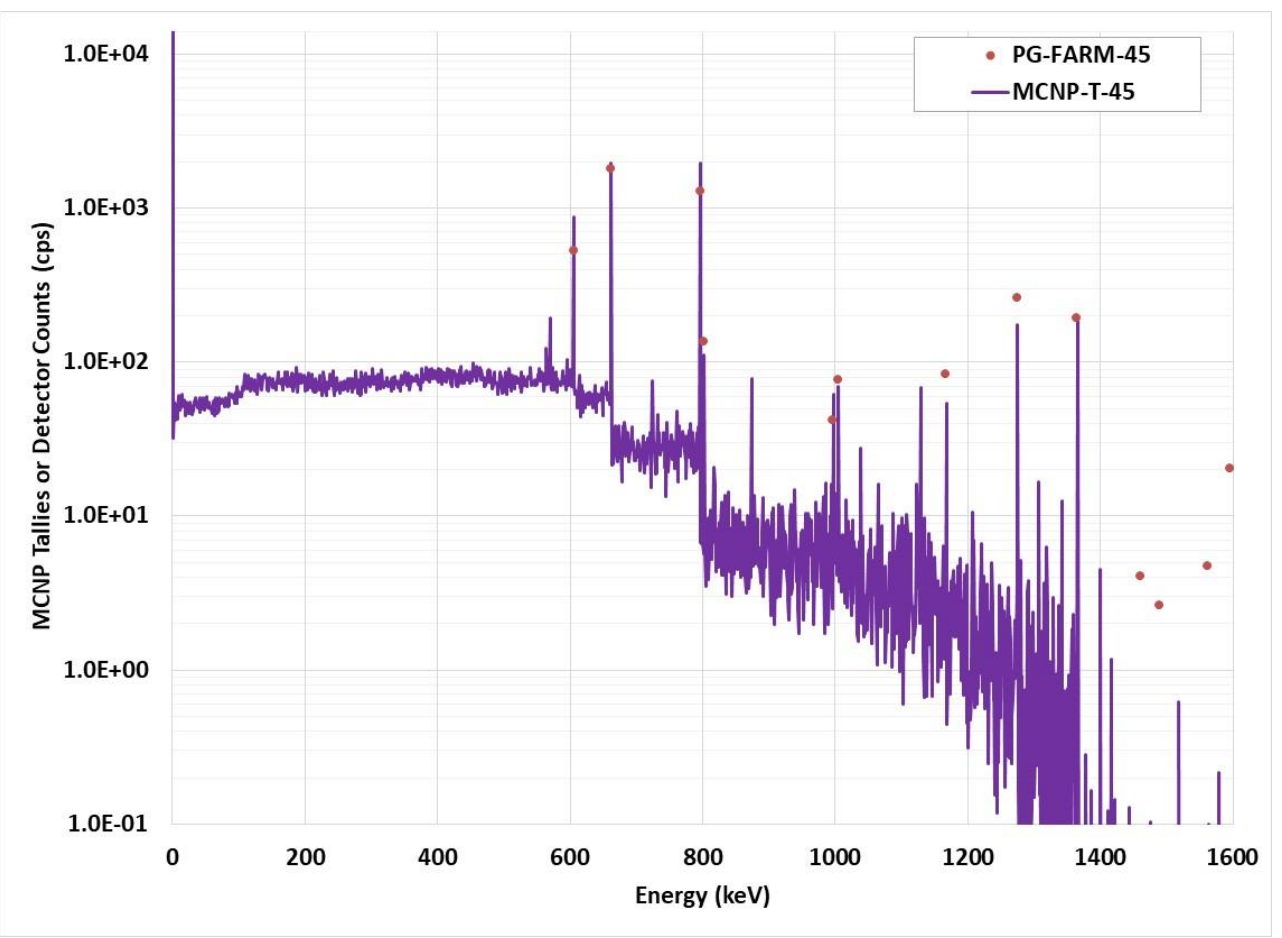

(a) 


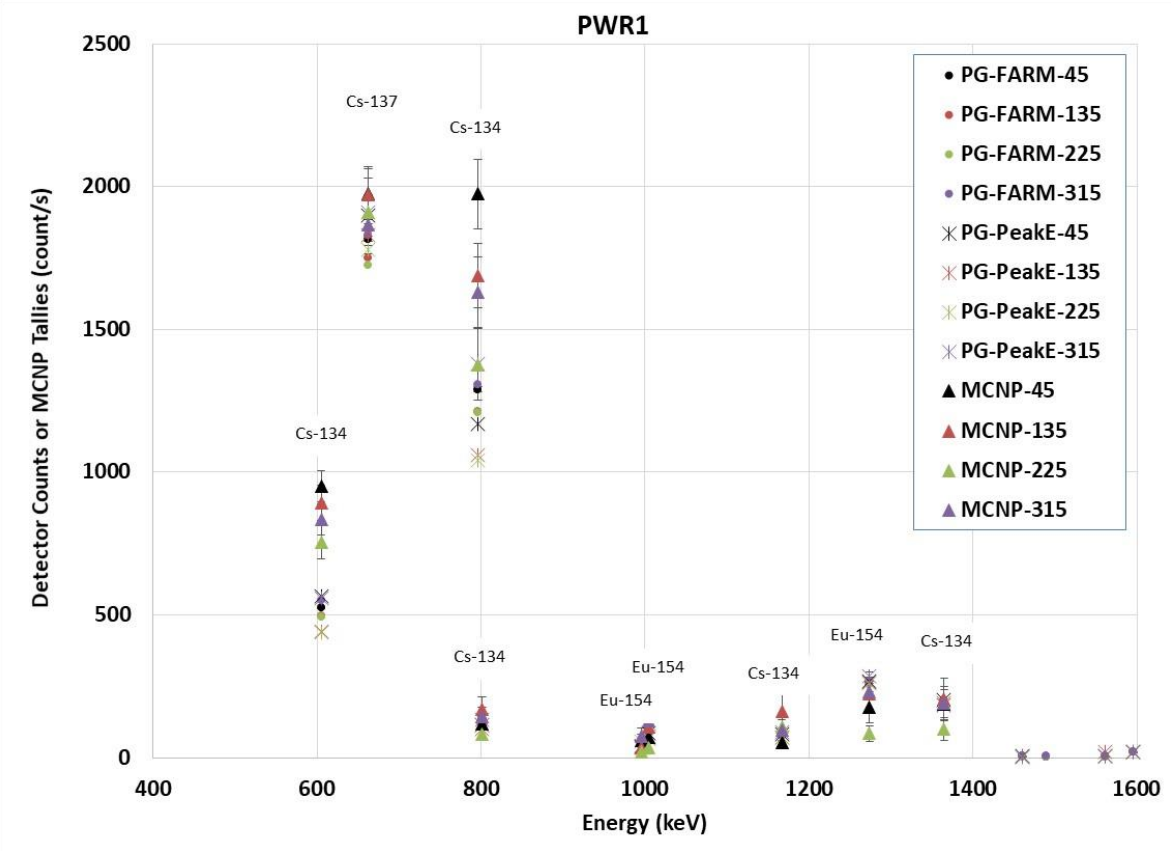

(b)

Figure 8 (a) MCNP6 tallied gamma energy spectrum from PWR1 fuel assembly by the HPGe detector. (b) MCNP6 tallied detector counting rates from the PWR1 fuel assembly at each gamma energy peak.

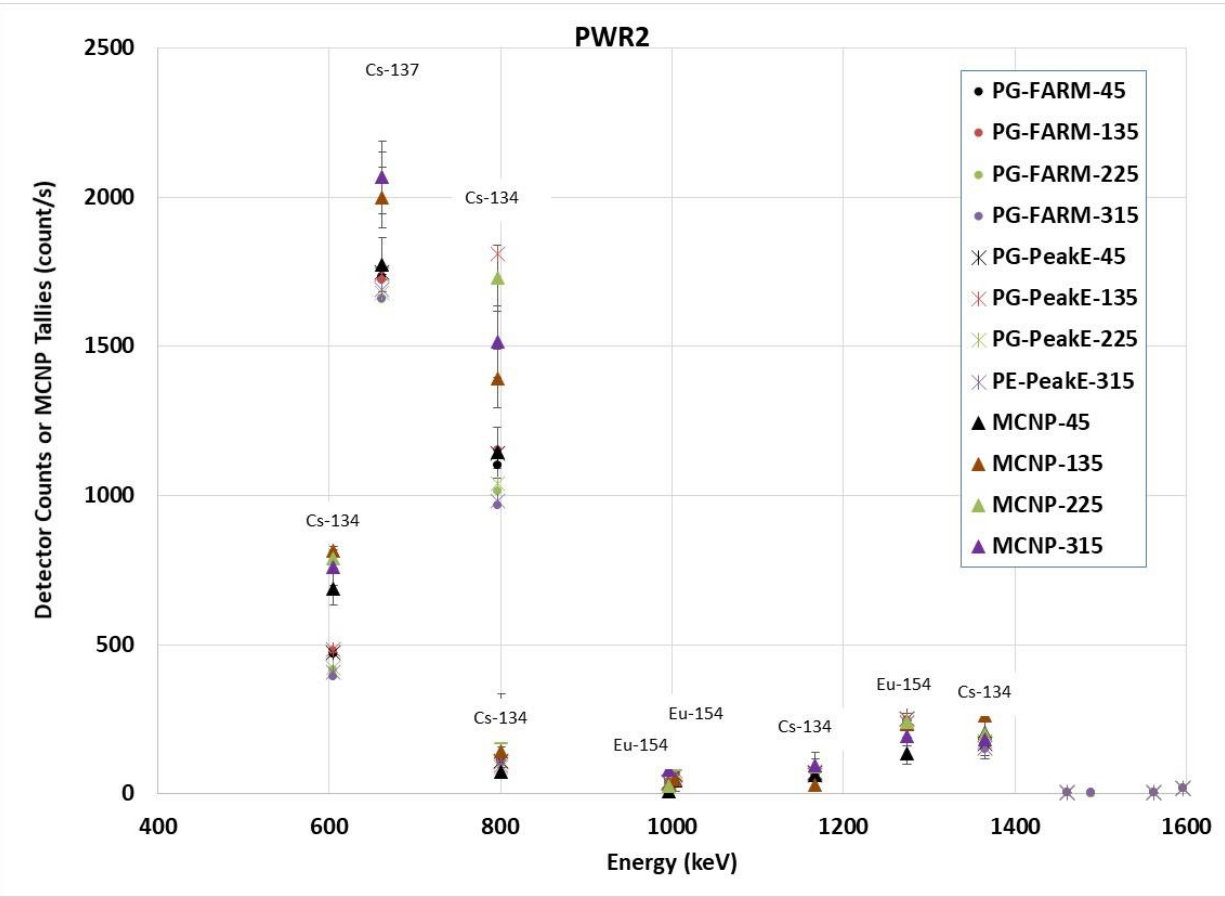

Figure 9 MCNP6 tallied detector counting rates for the SKB PWR2 fuel assembly at each energy peak. 
Table 1 MCNP calculated count rates at each peak for PWR1 and PWR2 fuel assemblies compared with the NDA data.

\begin{tabular}{|c|c|c|c|c|c|c|c|}
\hline \multicolumn{2}{|c|}{ Nuclide } & Cs-137 & \multicolumn{5}{|c|}{ Cs-134 } \\
\hline \multirow{7}{*}{ Energy Peak } & $662 \mathrm{keV}$ & $605 \mathrm{keV}$ & $796 \mathrm{keV}$ & $801 \mathrm{keV}$ & $\begin{array}{c}1167 \\
\mathrm{keV}\end{array}$ & $\begin{array}{c}1365 \\
\mathrm{keV}\end{array}$ \\
\hline \multirow{4}{*}{ PWR1 } & Exp & 1817.5 & 508.1 & 1208.1 & 124.3 & 78.6 & 189.9 \\
\cline { 2 - 8 } & uncertainty & 7.8 & 4.0 & 7.3 & 2.9 & 1.4 & 2.3 \\
\cline { 2 - 8 } & MCNP6 & 1901.2 & 857.2 & 1666.6 & 128.0 & 104.2 & 170.4 \\
\cline { 2 - 8 } & uncertainty & 30.2 & 47.8 & 143.4 & 21.7 & 25.9 & 27.6 \\
\cline { 2 - 8 } & C/E & 1.05 & 1.69 & 1.38 & 1.03 & 1.33 & 0.9 \\
\hline \multirow{5}{*}{ PWR2 } & Exp & 1704.1 & 442.8 & 1151.1 & 105.2 & 66.8 & 162.0 \\
\cline { 2 - 8 } & uncertainty & 7.7 & 3.4 & 7.0 & 2.7 & 1.2 & 1.9 \\
\cline { 2 - 8 } & MCNP6 & 1976.9 & 762.0 & 1445.0 & 151.4 & 69.7 & 212.4 \\
\cline { 2 - 8 } & uncertainty & 79.9 & 32.1 & 141.0 & 33.8 & 17.3 & 20.2 \\
\cline { 2 - 8 } & C/E & 1.16 & 1.72 & 1.26 & 1.44 & 1.04 & 1.31 \\
\hline
\end{tabular}

\section{Calculated Dose Rates}

Assuming that additional effort would yield similar agreement in the $662 \mathrm{keV}$ gamma flux results for the remaining 23 PWR assemblies, then the modeling approach used in this study can be considered validated for gamma flux calculations via the NDA measurements. This approach for modeling the radiation transport is a key component of a larger multi-step approach for dose rate calculations. Although the dose rates were not measured for these PWR assemblies, they were nevertheless calculated in this study for future use and reference. This mostly involved using flux dose rate conversion factors (namely, the 1991 ANS conversion factor [17]) that are energydependent. Table 2 shows the results for each fuel assembly. Figure 10 plots the calculated gamma dose rates according to its fuel burnup. 


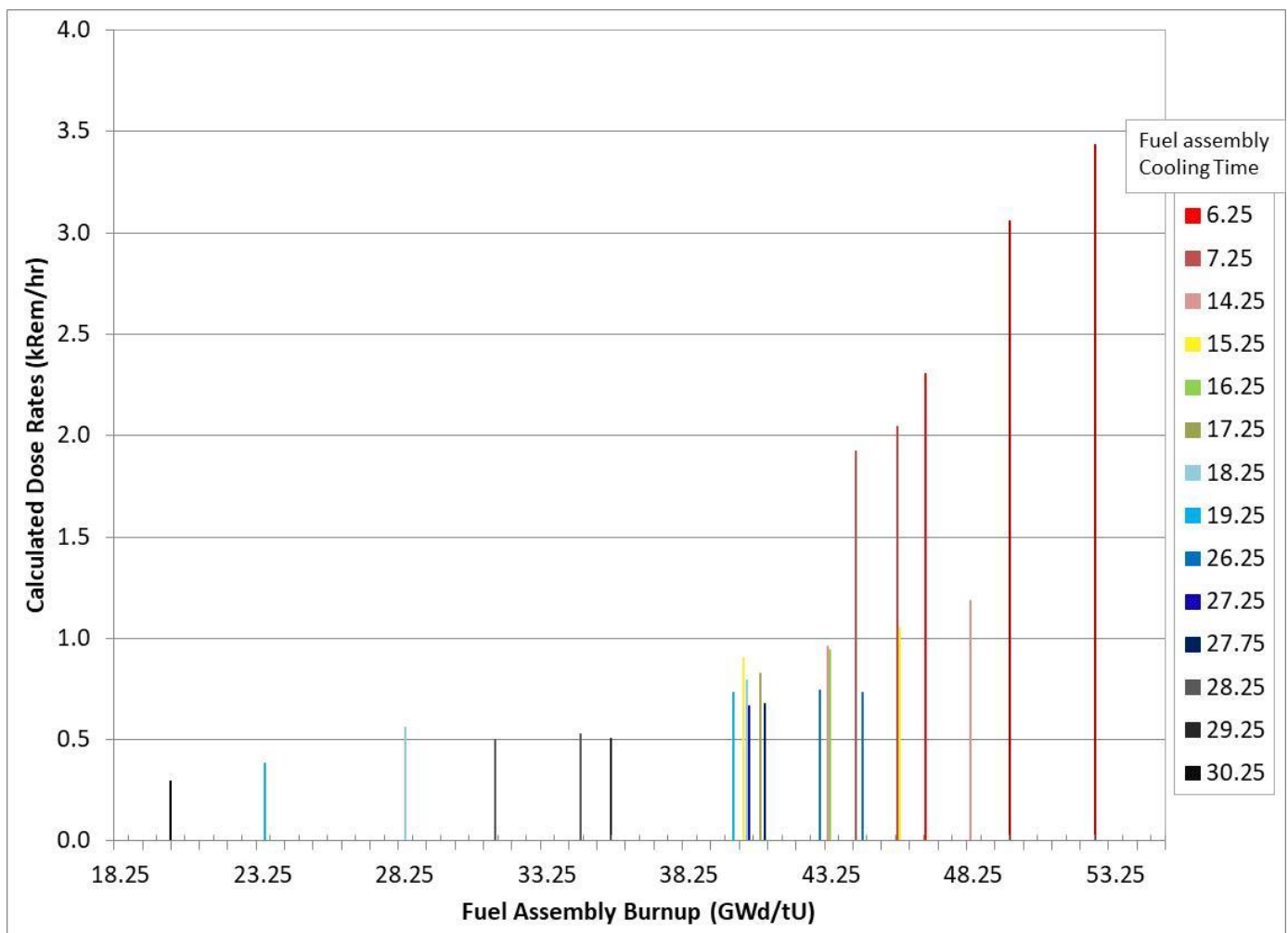

Figure 10: MCNP6 calculated gamma dose rates for the 25 SKB PWR fuel assemblies at the fuel center plane 1 meter away from the assembly surface.

In the figure, the different color bars represent the different cooling time periods of each fuel assembly after being discharged. Overall, the dose rates are higher for fuel assemblies with higher burnup, as expected. The fuel assembly dose rates also decrease significantly after a few extra years of cooling. To compare these results to those from the benchmark study [1], the results from fuel assembly PWR22 were selected since its characteristics (fuel burnup of $31.7 \mathrm{GWd} / \mathrm{tU}$ and decay time of 28 years) match closest to those from the reference example. PWR22's gamma dose rate of $\sim 5.02 \mathrm{~Sv} / \mathrm{hr}$ is entirely consistent with the results from that study.

Table 2 MCNP calculated gamma dose rates from the 25 PWR fuel assembly at the axial midpoint of the active fuel assembly and about 1 meter away from the closest surface

\begin{tabular}{|c|c|c|c|c|}
\hline Assembly & IE & BU & CT & Dose Rates \\
\hline ID & $($ wt U235\%) & $(\mathrm{GWd} / \mathrm{tU})$ & $(\mathrm{yrs})$ & $($ Rem/hr $)$ \\
\hline PWR1 & 4.10 & 52.630 & 5.4 & 3436.03 \\
\hline PWR2 & 3.93 & 49.555 & 5.4 & 3060.32 \\
\hline PWR3 & 3.69 & 48.175 & 14.3 & 1188.85 \\
\hline PWR4 & 3.93 & 46.873 & 6.3 & 2439.56 \\
\hline PWR5 & 3.94 & 46.866 & 6.4 & 2306.99 \\
\hline PWR6 & 3.60 & 45.658 & 15.3 & 1056.55 \\
\hline PWR7 & 3.94 & 44.483 & 7.3 & 1924.01 \\
\hline
\end{tabular}




\begin{tabular}{|c|c|c|c|c|}
\hline PWR8 & 3.30 & 44.375 & 26.1 & 731.47 \\
\hline PWR9 & 3.71 & 45.846 & 7.2 & 2048.11 \\
\hline PWR10 & 3.70 & 43.474 & 16.3 & 941.66 \\
\hline PWR11 & 3.51 & 43.225 & 14.3 & 962.30 \\
\hline PWR12 & 3.30 & 42.969 & 26.1 & 744.97 \\
\hline PWR13 & 3.20 & 40.920 & 27.5 & 678.91 \\
\hline PWR14 & 3.51 & 40.745 & 17.3 & 826.20 \\
\hline PWR15 & 2.80 & 40.473 & 27.1 & 668.04 \\
\hline PWR16 & 3.60 & 40.410 & 18.3 & 795.87 \\
\hline PWR17 & 3.70 & 40.294 & 15.1 & 902.38 \\
\hline PWR18 & 3.52 & 39.756 & 19.3 & 730.88 \\
\hline PWR19 & 3.20 & 35.027 & 29.4 & 506.76 \\
\hline PWR20 & 3.10 & 34.032 & 28.3 & 526.65 \\
\hline PWR21 & 3.10 & 34.019 & 28.3 & 526.74 \\
\hline PWR22 & 2.80 & 31.165 & 28.2 & 502.11 \\
\hline PWR23 & 3.60 & 28.499 & 18.3 & 562.99 \\
\hline PWR24 & 2.10 & 23.151 & 19.3 & 383.96 \\
\hline PWR25 & 2.10 & 19.607 & 30.4 & 297.03 \\
\hline
\end{tabular}

\section{Summary}

The MCNP photon transport simulation of the spent fuel assemblies and experimental facility showed very promising agreement (5\% to $16 \%$ error) of the calculated photon fluxes at the energy peak of Cs-137 $662 \mathrm{keV}$, which is the dominant radiation dose contributor in the spent LWR fuel assemblies. The agreement at other gamma energy peaks, particularly for the Cs-134 energy peaks is not as great as at the Cs-137 energy peak. The agreement ranges from a few percent to about $70 \%$ more in the MCNP tallied count rates. Due to the limited effort, MCNP simulations were performed only to the first two PWR fuel assemblies. Future simulation work to involve more spent fuel assemblies can provide more information to explain some of the differences or pinpoint the source of discrepancies in the above analysis. In addition, in these simulations, the detector model showed about $20 \%$ higher efficiency (54\% vs. 45\%) than that reported from the manufacturer. Future simulations with improved detector models may also improve the simulation results to the experimental data.

\section{Acknowledgements}

The authors acknowledge support of the Office of Nonproliferation and Arms Control, U. S. Department of Energy's National Nuclear Security Administration, and the Clab interim storage facility in Sweden. The measurements were performed as part of Action Sheet 50 "Spent Fuel NDA Research for Safeguarding Future Encapsulation/Repository Facilities." Action Sheet 50 of the Euratom-United States Department of Energy (DOE) agreement outlined the work in Sweden 
under the Cooperation Agreement on Nuclear Material Safeguards and Security Research and Development between the US Department of Energy, the European Atomic Energy Community, and SKB in Sweden.

The authors also would like to thank Dr. Holly Trellue (LANL) for her help providing the relevant information and guidance to complete our work.

\section{References}

[1] B. Feng, R.N. Hill, R. Girieud, R. Eschbach, "Comparison of Gamma Dose Rate Calculations for PWR Spent Fuel Assemblies," The Role of Reactor Physics Toward a Sustainable Future PHYSOR 2014, The Westin Miyako, Kyoto, Japan, Sep 28 - Oct 3, 2014 (2014).

[2] Y. Cao and B. Feng, "Validation of Gamma Dose Rate Calculation Methodology using the Morris and Turkey Point Measurements," ANL-19/06 (2019).

[3] R. Eschbach, B. Feng, etc., "Verification of Dose Rate Calculations for PWR Spent Fuel Assemblies," Proceedings of GLOBAL 2017 International Nuclear Fuel Cycle Conference, September 24-29, 2017 -Soeul (korea (2017).

[4] W.R. Lloyd, M.K. Sheaffer, and W.G. Sutcliffe, "Dose Rate Estimates from Irradiated Light-Water-Reactor Fuel Assemblies in Air," Lawrence Livermore National Laboratory, Livermore, CA, UCRL-ID-115199 (1994)

[5] H. Trellue, D. Henzlova, A. LaFleur, J. Eigenbrodt, "Spent Fuel Nondestructive Assay (NDA) Experiences and Successes," LA-UR-18-25995 (2018).

[6] Vaccaro, S., Tobin, Stephen Joseph, Favalli, Andrea, Grogan, Brandon R., Jansson, Peter, Liljenfeldt, Henrik, Mozin, Vladimir, Hu, Jianwei, Schwalbach, P., Sjoland, A., Trellue, Holly Renee, and Vo, Duc Ta. Sun . "PWR and BWR spent fuel assembly gamma spectra measurements". United States. doi:10.1016/j.nima.2016.07.032. https://www.osti.gov/servlets/purl/1287045. https://www.osti.gov/biblio/1287045

[7] A. Favalli, D. Vo, B. Grogan, P. Jansson, H. Liljenfeldt, V. Mozin, P. Schwalbach, A. Sjoland, S.J. Tobin, H. Trellue, S. Vaccaro, "Determining Initial Enrichment, Burnup, and Cooling Time of Pressurized-Water-Reactor Spent Fuel Assemblies by Analyzing Passive Gamma Spectra Measured at the Clab Interim-Fuel Storage Facility in Sweden," Nucl. Inst. Meth. Phys. Res. A, 820, 102-111 (2006).

[8] J. Hu, I. Gauld, "Spent Nuclear Fuel Modeling \& Simulation and Measurements," Spent Fuel Data Meeting at LANL, 2019.

[9] C. Willman, “Applications of Gamma Ray Spectroscopy of Spent Nuclear Fuel for Safeguards and Encapsulation.” Uppsala Univeritet, 2006.

[10] A. Hakansson and A. Backlin, "Non-destructive Assay of Spent BWR Fuel with Highresolution Gamma-ray Spectroscopy,” p. 36, ISSN 1104-1374, 1995. 
[11] S. Vaccaro et al., "PWR and BWR spent fuel assembly gamma spectra measurements," Nuclear Instruments and Methods in Physics Research Section A: Accelerators, Spectrometers, Detectors and Associated Equipment, vol. 833, pp. 208-225, Oct. 2016.

[12] Ludewigt, Bernhard, Mozin, Vladimir, Campbell, Luke, Favalli, Andrea, Alan W. Hunt, Reedy, Edward T.E., and Seipel, Heather. Mon . "Delayed Gamma-Ray Spectroscopy for Non-Destructive Assay of Nuclear Materials". United States. doi:10.2172/1236370. https://www.osti.gov/servlets/purl/1236370.

[13] M. Tarvainen, A. Backiin, and A. Häkansson, "Calibration of the TVO spent BWR reference fuel assembly: Final report on the joint Task JNT61 of the Finnish and Swedish Support Programmes to IAEA Safeguards," p. 51, STUK-YTO-TR 37, 1992.

[14] B. Gustafsson and R. Hagberth, "A CENTRAL SPENT FUEL STORAGE IN SWEDEN," p. 12, Proc. Of NEA Seminar on Storage of Spent Fuel Elements, Madrid, June 1978.

[15] D. Dunn, A. Pulvirenti, and M. Hiser, "Containment Liner Corrosion Operating Experience Summary Technical Letter Report - Revision 1,” p. 56, US NRC 2011.

[16] Harvey Shepard, private communication, June 2019.

[17] ANS American Nuclear Society, "American National Standard for Neutron and Gamma-Ray Flux-to-Dose-Rate Factors, “ANSI/ANS-6.1.1-1991 (1991). 


\section{Argonne}

\section{Nuclear Science and Engineering}

Argonne National Laboratory

9700 South Cass Avenue, Bldg. 208

Argonne, IL 60439

www.anl.gov 